\title{
Empower the Workforce, Empower the Company? Citizen Development Adoption
}

\author{
Doortje Hoogsteen \\ KPMG Netherlands \\ Hoogsteen.Doortje@kpmg.nl
}

\author{
Hans Borgman \\ University of Amsterdam \\ h.p.borgman@uva.nl
}

\begin{abstract}
IT departments today face a substantial backlog of business innovation-related activities and struggle with a shortage of software developers. Lowcode development platforms can help solve these issues by using technology to empower end-users without programming background to participate in the software development process. This trend is referred to as "citizen development." Through six case studies, this study advances our understanding of the factors that influence organizational citizen development adoption decisions. We use an extended technologyorganization-environment (TOE) framework, which enhances the explanatory power of the base TOE framework. Our results show that multiple risk perceptions, active top management support, projectbased business-IT alignment, centralized IT governance, and business network systems influence organizational citizen development adoption decisions. Based on the results, we discuss academic and practical implications and suggestions for future research.
\end{abstract}

\section{Introduction}

Nowadays, irrespective of their size and industry, organizations need to digitally transform their internal information systems to keep up with the rapid pace of the changing market requirements [1], [2]. This digital transformation wave has led to a significant increase in the demand for software and software developers. At the same time, IT departments are struggling to cope with the growing backlog of such business innovation-related activities [3]. Low-code development platforms (LCDPs) tools can help solve these issues. LCDPs are cloud-based software development platforms in where applications can be developed by minimalizing hand coding [3]. The LCDPs trend is marked by emphasis on the use of visual and straightforward interfaces with easy-tounderstand drag-and-drop features and simple logic for application development [3]-[5].

The use of this promising technology has exploded, as it has proven to bring many organizational benefits, such that LCDPs are now a catalyst even for business professionals who lack programming background to participate in the software development process [6], [7]. By empowering a wider group of people to participate in the development of applications with LCDPs, software demand problems could be mitigated in a cost-effective way [6], [8]. As LCDPs touch both the IT and the business domains, an interesting interplay between the two has emerged, which is referred as the trend of "citizen development" [8]. This new development paradigm has been widely embraced by LCDP vendors and organizations seeking to adopt it [8]. The commonly accepted definition of citizen development is "a business process that empowers non-IT employees to become software developers, using IT-sanctioned LCDPs to create business applications" [8], [9]. Although LCDPs are relatively new in the application development arena, the concept of citizen development is not entirely new within the academic literature. Rather, it is an extension of the substantially researched concept of end-user development [6], [10], [11]. The main difference between the two concepts is that end-user development generally has been limited to single users who create, modify, or extend a specific software artifact [11], whereas citizen development is focused on empowering groups of non-IT individuals to develop applications using LCDPs [6], [8], [9].

There are several advantages of citizen development. For example, citizen development (CD) empowers employees to use LCDPs to automate tasks [8] and secondly, it facilitates direct business knowledge integration as people can turn ideas directly into solutions. In this scenario, prototypes can be built easily without having to involve IT as an intermediary, which saves valuable time and misunderstandings between business and IT domains [11].

Despite the promising organizational benefits, deciding if and how to adopt citizen development is not an easy process [9]. Aside from market studies [9], [12] an in-depth analysis of citizen development adoption decisions at the organizational level is missing. There is limited insight on basic questions such as: How do organizations view citizen development? How and when do organizations decide to adopt this new wave of application development? What critical organizational factors influence citizen development adoption decisions? This research gap is crucial to be addressed because two conflicting situations are evident within many organizations: the software developer gap continues to rise, and many organizations are unsure how to empower non-IT individuals with technology in order to leverage employees' intellectual potential [13].

Empowering the workforce with the right technological tools is becoming increasingly important, as the new and future employees, which 
have grown up with the internet, are highly collaborative, use technology more naturally than earlier generations, and expect technology to be powerful and easy-to-use. Viewed in this light, citizen development can be a way for organizations to capitalize on these demographic and work culture trends [14]. In this study, we therefore aim to generate practical insight into factors that determine citizen development adoption decisions as well as how organizations can initiate this development trend.

Many theoretical models have been developed to assess organizational decisions to adopt new technologies. The technology-organizationenvironment (TOE) framework is one such model [15]. Although the TOE framework addresses three influential contexts, citizen development has some specific and unique characteristics whose impact on adoption decisions cannot be fully captured by the traditional TOE framework. Specifically, the sociotechnical character of the citizen development trend is generating a different view of adoption decisions. For example, according to LCDP experts ${ }^{1}$, the need to secure guidance is mandatory for preventing various risks. To accomplish this, cooperation between business and IT is required, and the involvement of external parties appears to be beneficial [16]. This notion is reinforced by an increase in the number of companies offering citizen development programs as a service [17]. These specific factors have enriched and expanded the TOE framework with additions in the organizational context as well as an extra "interorganizational context." These extensions facilitate a more complete understanding of citizen development adoption decisions, and our academical contribution is rooted in enhancing the explanatory power of the TOE framework, which is useful to derive practical and actionable recommendations related to this emerging trend. Our research objectives are reflected in the following research question: What technological, organizational, and inter-organizational factors influence citizen development adoption decisions, and how can organizations successfully decide how to adopt citizen development?

The remainder of this paper is organized as follows. Section 2 presents the literature review and concludes with six propositions. The research method is described in section 3 , and case studies are presented in section 4. Section 5 contains the cross-case analysis of each proposition. Section 6 discusses the findings and implications and offers suggestions for future research.

\section{Literature and Propositions}

The TOE framework and supporting literature acted as guidance throughout this research because it is

\footnotetext{
${ }^{1}$ Three experts were interviewed prior to the data collection to form an initial understanding of the citizen development trend, which is scarcely researched in the current literature.
}

a widely used organization-level and industryindependent adoption framework for assessing technology-related innovation adoption decisions [18]. The framework has proven its value with strong and consistent theoretical support [19]-[21]. To develop our understanding of citizen development adoption decisions, the technology, organizational building blocks and our extensions to them, and the interorganizational context are discussed and treated as the grounding set for our propositions, as depicted in Figure 1. The environmental context, which consists of external factors such as competitors, is not considered, as the impact of environmental contextual factors on technological innovations is widely recognized and well-accepted [19], [20], [22]. Therefore, our focus was purely on organizations' internal adoption decisions.

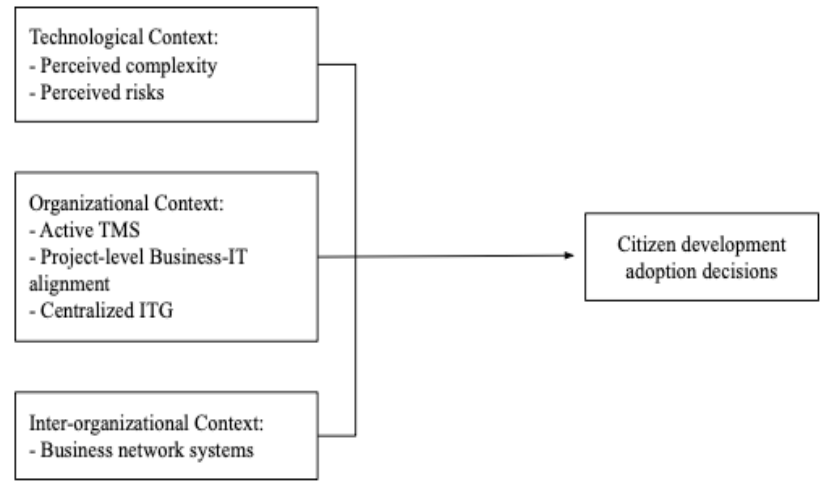

Figure 1. Research Framework

\subsection{Technological context}

The technological context dictates that adoption decisions are influenced by the pool of technologies internal and external to the firm [18]. The internal technologies are those that are currently used in the organization, and the external technologies are those outside of the organization but available in the marketplace. Organizational decisions to adopt new technologies are dependent on current resources and are made within the current technological ecosystem [21], [23]. The commonly accepted influential technological factors are perceived ease of use (complexity) and perceived risks. Perceived complexity defines the degree to which an innovation is perceived as easy to understand and use. Adoption decisions are hampered when employees perceive them as complex [19]. In contrast, lower complexity will generate employee confidence, which can stimulate organizations' adoption processes [19]. As previously discussed, in contrast with the more traditional application development methods, LCDPs visualize the underlying programming code and therefore generate straightforward interfaces with drag-and-drop features [4]. This has led to LCDP 
vendors claiming that application development with LCDPs is low in perceived complexity [9]. Research also shows complexity reduction for application development using LCDPs [3], [4]. Since low levels of technological complexity are positively related to adoption decisions [19], it is expected that organizational decision-making to empower businesspeople with LCDPs [read citizen development] will be positively influenced by it. This is reflected in the first proposition.

Proposition 1: The level of complexity of organizations' LCDPs positively influences citizen development adoption decisions.

Technological risk perceptions influence organizations' decisions to adopt such innovations [21]. With every innovation at least some risks are involved, but it is conceived that citizen development is related to multiple risks [24]-[26]. For example, research shows that software development outside of the IT domain, such as citizen development, is a real threat to data security and compliance issues and means that businesses are more likely to encounter cyberattacks [24]. The reason for this could be that most people have misplaced confidence regarding their knowledge of potential data privacy risks in information systems [27]. Moreover, the fact that many citizen developers do not have a high-level overview of the applications that are already available, a risk of duplication and thus of wasting scarce resources is genuine [8]. Therefore, several risks seem to be associated with citizen development, and due to the variety and number of risks, it is expected that multiple risk perceptions negatively impact organizations' decisions to adopt citizen development. This is reflected in the second proposition.

Proposition 2: Multiple risk perceptions regarding citizen development negatively influence citizen development adoption decisions.

\subsection{Organizational context}

Analyzing citizen development adoption from an organizational perspective involves organizational characteristics such as available resources, organizational size, and top management support [18]. Top management support (TMS) appears to be especially important for technology-related adoption decisions [28], [29] and refers to management guidance on operating processes by providing resources and explicit directions for managing the organization [18]. Since technological innovations are often the result of top-down decision-making, management automatically plays a crucial role in the innovation adoption processes. A distinction between active and passive TMS can be made, whereby passive support entails agreeing on a particular decision and an active role involves top management communicating opportunities and providing guidance for using the new technologies (e.g., training). The active role is proven to be critical for the awareness of the technology and ensures a fertile, safe, and supportive environment for innovations to be adopted [22], [29]. By attempting an active management support role, employees can recognize that citizen development-related behaviors are desired and this encourages employee knowledge sharing on adopting the platform [20]. Accordingly, it is expected that active TMS positively impacts organizational decisions on adopting citizen development, which is reflected in the third proposition.

Proposition 3: Active TMS positively impacts citizen development adoption decisions.

The literature shows that business-IT alignment is a common and long-standing obstacle for many organizations [30]. In recent decades, organizations have spent billions on IT investments that has led to rising concerns from businesses to IT and increased the stigma associated with two departments working separately [31]. This is highlighted by the LCDP experts, with all three stating the importance of a strategic fit between business and IT objectives for citizen development adoption. For example, one expert states, "Business-IT alignment is very important since the aspiration for citizen development often lies in the business and the resistance within IT departments." Consequently, disagreement on adopting the citizen development trend negatively affects adoption decisions [5].

To decide to adopt citizen development organizationwide, companies need to recognize if citizen development is a positive fit with their organization, and to realize this, successful alignment between the business and IT is needed. IT must understand, communicate, and guide the business in using the platform, since citizen development is under the supervision of IT. Thus, there must be a strategic fit on adopting citizen development, which refers to business-IT alignment at the project level [32]. Therefore, it is suggested that business-IT alignment at project level is essential for citizen development adoption decisions, which leads to our fourth proposition.

Proposition 4: Business-IT alignment at the project level is critical for citizen development adoption decisions.

The use of many technologies, such as LCDPs, has been transferred to business and has created a critical dependency on IT, requiring strong IT governance [33]. In this study, we define IT governance (ITG) as follows: the specification of the decision rights and accountability framework to encourage desirable behavior in the use of IT [34]. Since citizen development is "sanctioned by corporate IT," [8] IT departments are highly involved in organizations' citizen development adoption decisions, and thus clear ITG regarding citizen is development 
required. In general, organizations with well-governed IT, demonstrate a higher performance and better ITenabled decision-making [20], [35].

ITG decision structures can be centralized, decentralized, or federated [33]. Some of the literature stresses the importance of decentralized ITG for technological innovations [13], but when desirable employee behavior involves an enterprise-wide view, a more centralized ITG model is desirable [34]. Other studies claim that IT-decisions should be applied at portfolio level [8], [36]. Given these structures, it can be argued that citizen development is most suitable for a centralized ITG structure at portfolio level [read citizen development level] as centralized decisionmaking will increase clarity, coordination, and control for citizen development, which are all important aspects since they can mitigate related risks [37]. A central decision-making hub concerning citizen development would thereby reduce enterprise IT landscape by being a single suitable platform and ensure clarity by involving one dedicated team that maintains contact with the LCDP vendors and other involved parties. Consequently, it is expected that one central IT governance for citizen development will enhance organizations' decisions to adopt citizen development. This makes ground for the fifth proposition.

Proposition 5: Centralized ITG decisionmaking for citizen development is beneficial for its adoption

decisions.

\subsection{Interorganizational context}

In this study, interorganizational context involves the relationship between an organization and an external party. Every organization has interorganizational relationships, such as longitudinal contractual software-vendor partnerships, and besides providing the software, most vendors today also assist with adoption processes of acquired software. Previous research on cloud adoption confirms the importance of these inter-organizational business networks, owing to many cloud service providers arranging change agents, providing training sessions, and addressing potential problems [19], [21]. Thus, the intensity of these relationships leads to stronger collaborations referred to as business networks systems [38]. Consequently, LCDP vendors have an important role in the success of the platform [22], [29], but despite vendor support, research shows that organizations find it difficult to accomplish desired LCDP adoption after the implementation phase [9]. Usability issues and lack of internal communication regarding the opportunities of LCDPs are identified causes [5], [7]. Accordingly, when IT departments have trouble realizing high LCDP adoption levels, adoption decisions for citizen development are not in the foreground. In addition to vendors, other actors can enter the business network system to assist with such adoption decisions [38]. External parties specialized in LCDPs could, for example, assist by assessing if the organization is wellprimed for citizen development. This is recommended since, for many organizations, there are unknown elements related to citizen development adoption [8]. Specialized LCDP vendors and other external organizations are aware of these unknown elements and can offer direction for well-considered decisions. To conclude, prior mentioned business network systems in terms of vendor support or third-party guidance could improve citizen development adoption decision-making. This provides the foundation for our final proposition.

Proposition 6: Business network systems are critical for citizen development adoption decisions.

\section{Research method}

This study was of exploratory nature and was based on six case studies and three expert interviews. A multiple case study design is an appropriate research method for studying novel phenomena and to find answers to "why" and "how" questions [39]. For each case, two interviews were conducted, with employees from different places in the organizational hierarchy (e.g., chief technology officer, IT consultant, IT manager, product owner, and business analyst). Fifteen semi-structured interviews constituted our primary source of evidence. Semi-structured interviews are aimed to obtain more in-depth knowledge into the specific contexts of the organizations and encouraged the participants to answer and explain questions, without the interviewer directing the answers. In addition, this approach allowed for follow-up questions, which enabled insightful new findings [40]. The interview evidence was strengthened with expert opinions, published literature, and documentation available with the case organizations. This method is considered a technique to seek data triangulation, and it enhances the reliability and validity of this research [39]. The interviews were conducted in April, May, and June 2021 and were held in English or translated from Dutch to English. Due to the COVID-19 lockdown restrictions, all interviews were held via approximately 45-minute lasting video calls and prior to the interview, all participants gave informed consent. Subsequently, the video-recorded interviews were transcribed, coded, and analyzed using the Atlas.ti software [41]. Table 1 provides an overview of performed within-case analysis method. To compare the discovered patterns between the cases, a cross-case analysis was performed. Additionally, to check the objectivity of the coding scheme and improve reliability, the coding of interviews from two cases were analyzed by an independent analyst.

Table 1. Illustration of Interview Coding (Case 1, Respondent A, Proposition 1)

Proposition 1: Perceived low complexity of LCDPs positively influences citizen development adoption decisions. 
Findings: The reason for using LCDP is replacing legacy systems and state that Outsystems is not suitable for citizen development in their organization, since developing applications requires technical knowledge. As the IT Manager states: "Citizen development, it's a very nice term -cynically speaking-, but we are not ready for it, because professional developers can still build bad applications with Outsystems."

Quotations:

Quote 1: "Citizen developers can work with the standard modules from Outsystems, but if adjustments need to be made in these standard modules, then people with more background knowledge must step in."

Quote 2: "Citizen development is not for everybody, because not everybody can actually use that technology."

Quote 3: "One of the difficulties that citizen developers encounter are integrations for combining different data sources, which are too technical for citizen developers."

\section{Cases}

For the selection of the cases, six cases from different sectors were chosen to grasp a complete picture of the complex socio-technical concept of citizen development and investigate if there are differences in terminology between sectors. The cases for this study were carefully selected by applying the following case criteria: all cases underwent a large and recent implementation of at least one prominent, market leading LCDP vendor in the period between 2017 and 2020. According to Gartner's 'Magic Quadrant' for enterprise LCDPs [37], the prominent market-leading LCDP- vendors are Outsystems, Mendix and Microsoft. Accordingly, all cases utilize one of these vendors for their low-code strategy. To be able to compare the cases with each other, only corporate organizations were selected since it has been widely acknowledged that organizational size is an important facilitator for technology-driven adoption decisions [20], [23]. The comparability is also increased as all organizations were at least partly headquartered in the Netherlands. These common case features improve the generalizability and replicability of this study and make it possible to find answers to our research question [39]. Due to privacy reasons, for two cases, referring to their sector, anonymized names were used throughout this study. In Table 2 all cases are presented, including descriptive information of each case.
Table 2. Case study overview: descriptive information per case

\begin{tabular}{|c|c|c|c|}
\hline Case ID & $\begin{array}{l}\text { Function } \\
\text { participant }\end{array}$ & $\begin{array}{l}\text { LCDP } \\
\text { Vendor }\end{array}$ & $\begin{array}{l}\text { Reason to implement } \\
\text { LCDPs }\end{array}$ \\
\hline $\begin{array}{l}\# 1 \\
\text { Randstad } \\
\text { Group }\end{array}$ & $\begin{array}{l}\text { 1. IT developer } \\
\text { 2. IT manager }\end{array}$ & $\begin{array}{l}\text { Outsyste } \\
\text { ms }\end{array}$ & $\begin{array}{l}\text { RAD }^{2}, \quad \text { replacing } \\
\text { legacy systems \& } \\
\text { improve UX }\end{array}$ \\
\hline $\begin{array}{l}\# 2 \\
\text { Royal } \\
\text { Dutch } \\
\text { Shell }\end{array}$ & $\begin{array}{l}\text { 1. Product owner } \\
\text { 2. Senior factory } \\
\text { operator (non-IT) }\end{array}$ & Microsoft & $\begin{array}{l}\text { Risk management \& } \\
\text { employee } \\
\text { empowerment }\end{array}$ \\
\hline $\begin{array}{l}\text { \#3. } \\
\text { HTM }\end{array}$ & $\begin{array}{lr}\text { 1. } & \text { IT-consultant } \\
2 . & \text { Hospitality } \\
\text { manager (non-IT) }\end{array}$ & Mendix & $\begin{array}{l}\text { Enhance enterprise } \\
\text { resilience \& employee } \\
\text { empowerment }\end{array}$ \\
\hline $\begin{array}{l}\# 4 \\
\text { FMCG }\end{array}$ & $\begin{array}{l}\text { 1. Product owner } \\
\text { 2. IT-consultant }\end{array}$ & $\begin{array}{l}\text { Outsyste } \\
\mathrm{ms}\end{array}$ & \begin{tabular}{lr} 
Replacing & \multicolumn{2}{r}{ legacy } \\
systems, & RAD \& \\
enhancing & enterprise \\
resilience &
\end{tabular} \\
\hline $\begin{array}{l}\# 5 \\
\text { Beer- } \\
\text { And- } \\
\text { Beverage }\end{array}$ & $\begin{array}{l}\text { 1. Busines analyst } \\
\text { 2. Global product } \\
\text { owner }\end{array}$ & $\begin{array}{l}\text { Microsoft } \\
\& \\
\text { Outsyste } \\
\text { ms }\end{array}$ & $\begin{array}{l}\text { Process automation \& } \\
\text { employee } \\
\text { empowerment }\end{array}$ \\
\hline $\begin{array}{l}\# 6 \\
\text { KPMG }\end{array}$ & $\begin{array}{l}\text { 1. Tech consultant } \\
\text { 2. Tech Solutions } \\
\text { director }\end{array}$ & $\begin{array}{l}\text { Microsoft } \\
\& \\
\text { Outsyste } \\
\mathrm{ms}\end{array}$ & $\begin{array}{l}\text { Advisory, enhancing } \\
\text { enterprise resilience \& } \\
\text { employee } \\
\text { empowerment }\end{array}$ \\
\hline
\end{tabular}

\section{Cross-case analysis}

Cross-case evidence is sought for each of the propositions and guided by direct quotations from the interviews, literature, documentation and expert interviews, which further enhance the internal validity and generalizability of this study [40]. Figure 2 presents an adoption vs. ambition matrix, which plots each case in this matrix. Plotting the cases is based on the findings derived from the interviews and the matrix helps to compare the cases. An example is provided by the IT consultant of HTM (case 3): "At the moment, the LCDPs developers are mainly in IT, but the ambition is absolutely to get businesspeople developing applications as well." Consequently, this case is plotted as lowest in the top-right quadrant.

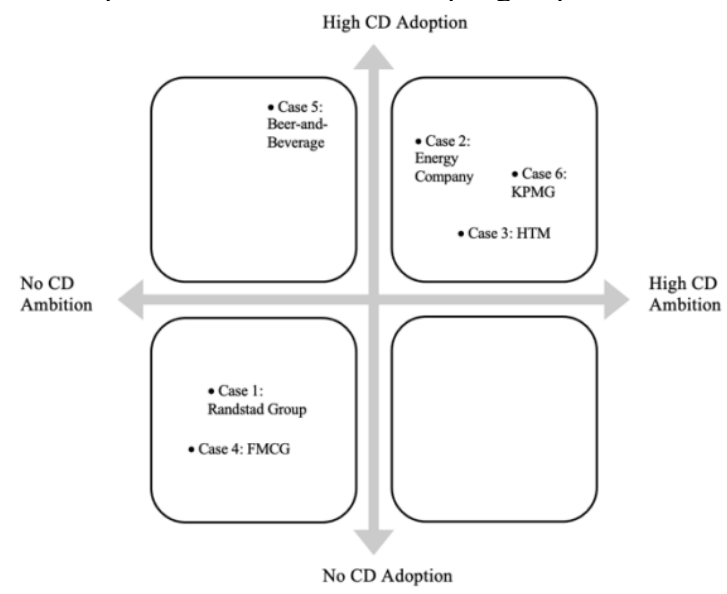

Figure 2. Adoption Vs. Ambition Matrix

\footnotetext{
${ }^{2}$ Rapid Application Development (RAD)
} 


\subsection{P1: (Perceptions of) Low complexity}

According to the literature and LCDP vendors, the LCDP- software empowers end-users to create applications through easy-to-follow drag-and-drop user interfaces [4], [9]. Our expectation that this would positively influence adoption decisions do not match our findings, since in none of the cases- and expertinterviews support was found for this reasoning. The complexity of citizen development was multiple times metaphorically explained: "You should see citizen development as building a house. You cannot build a solid and safe house without a proper foundation.", "Can you drive and participate in traffic without knowing the traffic rules?" and "Can you fix a car if you are not a mechanic?". Each case demonstrated technological hurdles organizations could experience when starting with citizen development. Interviewees explained that many difficulties had to do with dataaccess issues, software integration difficulties, legacy systems, lack of technological knowledge, customizing applications and organizational readiness regarding citizen development. For example, the IT manager of Randstad Group (case 1, Table 1) clearly stated that developing applications with LCDPs still requires technical background or at least some intensive training: "We see that there are already difficulties with onboarding technical employees in the Outsystems environment. We, therefore, don't burn our hands at presenting the low-code platform to the business." And the IT developer of the company intensifies this by explaining "One of the difficulties that citizen developers may encounter are the possible integrations that must be performed to combine different types of data. These tasks are way more technical and not realistic for people without technical knowledge." The findings underpin the notion that for developing applications with LCDPs, organizations still need employees with some sort of technological skills and 'modular' [read 'logical'] thinking. The senior factory operator, a production line employee, of Energy Company (case 2) exemplifies this as he explained his difficulties starting with LCDPs: "In the beginning I especially struggled with understanding how to think in flow-charts. Therefore, I don't think building lowcode applications is so simple that anyone can become a citizen developer straight away". To conclude, our results show that the LCDPs are not perceived to be low in complexity and as a result, do not influence adoption decisions in the proposed direction.

\subsection{P2 Perceived risks}

All cases, except for the second case in which only one risk was specified, reported multiple risks perceptions regarding citizen development. However, it is interesting to notice that the cases without motivation to adopt citizen development (case 1 and 4) do not report more risks as compared to the cases that adopted (or planning to) citizen development. These results suggest that risk perceptions are not necessarily decisive for citizen development adoption.

Yet all the cases did show that risk perceptions influence organizational decisions, but not automatically in a negative way. Instead, those risk perceptions are used to shape guidelines around citizen development initiatives, which is exemplified by the global product owner of Beer-and-Beverage: "As a governance and security team, we try to make everything secure and within our set limits, not much can happen." These findings make it particularly interesting to capture the identified risks and for that reason, the multiple risk perceptions are visualized using a Sankey diagram, as shown in Figure 3.

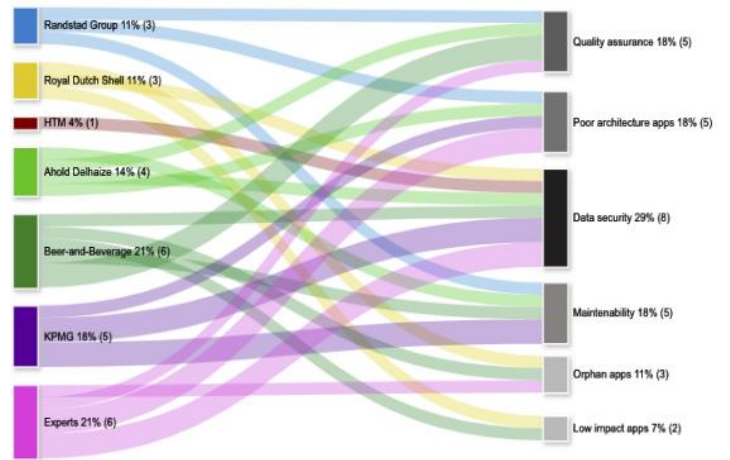

Figure 3. Identified Perceived Risks

All interviewees revealed their concern that without clear guidance and governance citizen development could lead to data security issues and therefore risky applications. The smart tech solutions director (case 6) summarizes the most mentioned risks by describing them as an "iceberg": "The democratization of technology and therefore citizen development comes with risks. We explain these risks with the citizen development iceberg, which is an analogy of visible and invisible risks. The underwater risks [read 'unknown'] are mostly related to data governance, support and application quality." The two cases without citizen development adoption (case 1 and 4) perceive most risks in terms of data - and maintenance related problems (Figure 3). Both stated that citizen development causes many valueless applications that are poorly constructed in terms of architecture, which results in maintenance and transferability issues. This is exemplified by the IT consultant of Randstad Group (case 1): "Every application needs maintenance, which can be a risk because we have to hire more and more specialists to maintain all applications. Then, consider how much maintenance you need to have with citizen development."

\subsection{P3 Active top management support}

Case findings show that active TMS affects citizen development adoption decisions since management departments largely determine whether resources are given for citizen development 
The cases with citizen development adoption or ambition (case 2, 3, 5 and 6) all received strong TMS for setting up citizen development organization wide. In contrast, within in the bottom-left cases (1 and 4), management wasn't even aware of the citizen development trend. Three cases (2, 3 and 6) showed most evidence for the positive influence of TMS as these organizations designed an organizational-wide citizen development program supported top management. The smart tech solutions consultant of KPMG (case 6) declares: "The global citizen development program started because our management recognizes that citizen development is a way to empower the current- and future workforce." The smart tech solutions director of the company reinforces this claim by stating: "We're enabling KPMG citizen developers to acquire sought-after skills that help them develop strong and future-proof careers." Similarly, Energy Company(case 2) recently started the 'Do It Yourself' (DIY) program and HTM (case 3) started 'Mendix Masters', all programs that received active TMS by communicating frequently about the citizen development initiatives and by providing. An interesting finding is derived from Beer-and-Beverage (case 5) where, instead of a top-down, a bottom-up initiative regarding citizen development emerged. PowerApps became available for everyone in the organization as this was one of the inclusive tools within their Microsoft contract. This resulted in an overwhelming number of applications created by citizen developers. The global product owner of the company described this unfoldment as follows: "When the platform became available employees started building applications, which resulted in 4000+ applications. The decision by management to create a global governance team for this [citizen development] was made after there were already 4000+ applications." She additionally expressed that the global governance team was set up to control the huge influx of citizen development, which had caused maintenance problems and that, in retrospect, they would be better off using a structured top-down citizen development approach with well-thought-out guidelines.

\subsection{P4 Business-IT alignment}

In general, IT and business departments became more aligned with the use of LCDPs and citizen development since LCDPs are, in comparison to traditional software development tools, more tangible to the business [3]. This is supported by our findings, as it was acknowledged that citizen development positively impacts the cooperation and comprehension between business and IT. Multiple interviewees stated that citizen development has led to a greater understanding of the business to the work that IT does. The business consultant of HTM nicely illustrates this by stating: "Due to the use of LCDPs in the business, the value of IT is becoming increasingly clear to the employees in the business." These findings show its effect of citizen development on project-level business-IT alignment, but for adoption decisions to be made, IT and business must be aligned beforehand. Our case findings demonstrate that strategic alignment for citizen development were not present in the no adoption cases (cases 1 and 4). The findings from Randstad Group (case 1) demonstrate this, showing that the use of LCDPs is only within the IT domain and the interviewees expressed their opinion by stating that LCDPs for the business does not have any added value. The IT specialist declared: "- long thought ...cooperation with the business for application development is tricky. Randstad Group are divided into IT and business and the business just has to indicate what they want from IT.". Alike, the IT consultant of FMCG (case 4) expresses: "The application development domain rests in IT and this will not change in the near future." The other cases, including case 2, 3, 5 and 6, demonstrated contractionary findings. All these 'adoption' cases mentioned that alignment on strategic goals regarding the use of LCDPs is important for citizen development decisions since both domains are dependent on each other. The hospitality manager of HTM underpins this by explaining: "The good cooperation with IT about LCDPs [read project-level] certainly made me start working with low-code." Additional findings were derived from KPMG (case 6) as the smart tech consultant explained: "Some colleagues noticed that if IT does not support citizen development, people will develop applications themselves, which eventually leads to shadow IT." This finding additionally shows that business-IT alignment on project-level is important as it prevents potential related risks of citizen development from emerging.

\subsection{P5 Centralized IT-Governance structures}

Across the six cases and the expert interviews, support was found for the fifth proposition, suggesting that centralized ITG for citizen development foster citizen development adoption decisions. All ambition or adoption cases (case 2, 3, 5 and 6, Figure 2) have centrally organized IT decision-making when it concerns citizen development. The senior operator of Energy Company (case 2) explains: "There is a strict and central IT governance regarding citizen development. Various 'development zones' are created by this governance (green, orange and red). This governance makes it clear to citizen developers where they are allowed to develop applications." Another example of support is given by the global product owner of Beer-and-Beverage (case 5) as she discloses: "Recently, we have been working on global governance and the adoption of citizen development and we as a global governance team are owning the Microsoft platform. We check all the rights behind the 
scenes, block certain accesses and provide guidance, which is the reasons why citizen development is supported by top management now." The director of KPMG (case 6) reports similar importance of a centralized governance by stating: "We want to be ready for the future workforce generation, and we do this by creating a well-governed global [read centralized] citizen development program." Contrary, case 1 and 4 (bottom-left, Figure 2) have both decentralized ITG decision-making structures and the findings show an absence regarding citizen development adoption decisions. Both cases stated that their organizations are too complex (in terms of organizational size and different business-units) for citizen development to be off any value. This is exemplified by the IT consultant of FMCG (case 4): "FMCG is such a big organization that we can't arrange our ITG centrally. We have different technologies and decision-making processes per department." Hence, the differences between the cases with centralized ITG decision-making in comparison with decentralized, give support for the notion that citizen development decisions are positively influenced by centralized ITG decision structures.

\subsection{P6 Business network systems}

This section highlights the importance of business network systems for citizen development decisions. Both HTM and KPMG (case 3 and 6) were assisted by an external partner for making strategic choices regarding citizen development.

HTM (case 3) benefitted from third party intervention to help in making decisions on how to harness the creative potential of their employees. The IT business consultant of the company stated: "We have an implementation partner, who helps us intensively with the realization of citizen development. They have the necessary knowledge and experience, so therefore they help us making the right decisions." This inter-organizational relationship has led to the socalled "Mendix Masters" program in which every motivated employee could participate in to learn the basics of application development with the Mendix platform. Afterwards a certificate can be obtained, which provides access to the company's Mendix platform. The hospitality coordinator of HTM who a perfect example of a citizen developer, illustrates how he benefitted from this third-party guidance: "I have direct contact with one of the consultants from our implementation partner to whom I can send my applications to. Thereby, I am part of the Mendix Master's program, which is organized by our partner. I look forward to this training! -enthusiastic tone-."

Alike, KPMG (case 6) shows similar findings, since they have partnered up with an external company specialized in citizen development. The smart tech consultant explained: "We have a third party (the Project Management Institute) that helps with setting up citizen development globally." The mantra of this third-party company states: "Learn how to unlock the potential of citizen development in your organization." In these two cases, third-party interventions have been crucial for citizen development decisions, since both companies acknowledged that for citizen development to become a success, by expert-driven guidelines should be drafted.

However, both at Energy Company (case 2) and Beer-and-Beverage (case 5), it was also unanimously decided to foster citizen development (e.g.: DIY program), but within their organizations, no third-party intervention was arranged. Both companies do state to have regular vendor-support for the more functionally oriented inquiries. To conclude, our results point out that business network systems in terms of vendor-support or third-party intervention positively influence citizen development adoption decisions.

\section{Discussion}

This research aimed to prove new insight into the factors that influence organizational decisions to adopt citizen development or not and how organizations can successfully adopt it. The results supported our extended TOE framework and address the first part of our research question: What technological, organizational, and interorganizational factors influence citizen development adoption decisions within organizations?

Our results supported the impact of the following factors on citizen development adoption decisions: "multiple risk perceptions," "active TMS," "projectbased business-IT alignment," "centralized ITG decision structures," and "business network systems." For the technology context, contrary to our expectations, none of the cases showed support for the first proposition, namely that low complexity of LCDPs would promote citizen development adoption decisions. In each case, it was mentioned that building business applications with LCDPs is still a complex process that demands specific abilities, which in turn, hamper organizational adoption decisions. An interesting finding as it is opposite to the opinion of the LCDPs vendors. Follow-up research looking at this inconsistency more closely will be necessary to determine if this view is primarily made from a commercial perspective or whether there is another explanation at play.

The second part of our research question concerns best practices for citizen development adoption decisions to ensure that the benefits of citizen development, such as application delivery velocity, business agility, and reduction of the software developer talent gap, are achieved. Our case findings, together with the discussed literature and expert opinions, generate several important implications.

An important first implication is that there is not a onesize-fits-all approach for organizations deciding to adopt citizen development. Organizations must select the right use cases for citizen development, and this 
recommendation has three identified dependencies: type of technology, type of organization, and type of end users. Some LCDPs require less technological knowledge and have few integration issues. For example, for end users whose organizations have a long-term partnership with Microsoft, using PowerApps is relatively easier to adapt to because the users are familiar with the look and feel of the platform. The type of organization matters because organizations in which frequent innovation is considered desirable and important (cases 2, 3, and 6) have a more positive attitude toward citizen development and thus impact decision-making for adopting it. Lastly, organizations should consider what type of citizen development they want to adopt. Our findings in this regard are consistent with the literature and market studies - it appears there is no single definition of citizen development [8], [10]. In some organizations, it only involves developing simple applications for personal use, whereas in other organizations, citizen development entails the creation of organization-wide and more complex applications.

The second implication is establishing organizationwide guardrails while undertaking citizen development, since our results, and previous research on end-user development [42], demonstrated potential risks, as illustrated in Figure 3. Organizations must place high emphasis on developing a carefully and thoroughly considered plan that is endorsed by the top management. This aligns with recent research that indicates that end users must be "empowered by design" [43]. The same principle is exemplified by KPMG's (case 6) "trust by design" principle. The importance of this philosophy is additionally highlighted by the fourth case, which had no "design" and resulted in an uncontrolled situation where over 4,000 applications were developed in just one month. Designing the guardrails is not an easy task, as a balance must be struck between autonomy and control [44]. Our findings show that business network systems could help in this pursuit [38]. External organizations that specialize in LCDPs and citizen developers are often more aware of the less-visible elements that can impact citizen development adoption and success. Therefore, specialized guidance will make it more likely that the intended benefits are achieved while the risks are reduced. While designing a citizen development program, it is crucial to educate not only the business professionals but also IT department, as our study points out that alignment between the two domains is essential. The third and last implication stems from our additional case findings (cases 3, 5, and 6) and the research on the importance of social interactions for technological adoption decisions [44]. By building an online community, social interactions such as knowledge-sharing and guidance exchange between professional and non-professional developers can be fostered. In addition, such communities raise awareness for the program and provide a platform to share success stories and the lessons learned [43].

Although our study provides many valuable insights into the emerging trend of empowering employees through LCDPs, there are areas of improvements. Our study had a cross-industry setup that made it possible to compare the results across industries. Considering that industry type also has an impact on technology adoption decision-making [18], future research could focus on researching citizen development within a particular industry. Also, future research can (probably) take place physically again by visiting the organizations in question. In this way, more observations can be included, which will also strengthen the quality of the research. Another avenue for subsequent research arises from the fact that three of our cases (cases 3, 4, and 5) were still developing or had just commenced their citizen development initiatives. It would be valuable to conduct a longitudinal study to explore how such programs develop over time. Lastly, examining questions such as "Do organizations reap benefits from implemented citizen development initiatives?" and "Do the risk perceptions identified in this study change over time?" can help obtain a more comprehensive understanding of employee empowerment through LCDPs.

\section{Literature}

[1] R. Alt, J. M. Leimeister, T. Priemuth, S. Sachse, N. Urbach, and N. Wunderlich, "Software-Defined Business," Bus Inf Syst Eng, vol. 62, no. 6, pp. 609-621, Dec. 2020.

[2] C. Chiang and C. Bayrak, "Legacy Software Modernization," in 2006 IEEE International Conference on Systems, Man and Cybernetics, 2006, 2, 1304-1309.

[3] R. Sanchis, Ó. García-Perales, F. Fraile, and R. Poler, "Low-Code as Enabler of Digital Transformation in Manufacturing Industry," Applied Sciences, vol. 10, no. 1, Art. no. 1, Jan. 2020.

[4] R. Waszkowski, "Low-code platform for automating business processes in manufacturing," IFACPapersOnLine, vol. 52, no. 10, pp. 376-381, 2019.

[5] J. Bratincevic and J. R. Rymer, "When and How To Modernize Core Applications Using Low-Code Platforms," p. 13, 2020.

[6] F. Paternò and C. Santoro, "End-user development for personalizing applications, things, and robots," International Journal of Human-Computer Studies, vol. 131, pp. 120-130, Nov. 2019.

[7] F. Paternò, "End User Development: Survey of an Emerging Field for Empowering People," ISRN Software Engineering, vol. 2013, pp. 1-11, Jun. 2013.

[8] M. Oltrogge et al., "The Rise of the Citizen Developer: Assessing the Security Impact of Online App Generators," in 2018 IEEE Symposium on Security and Privacy (SP), May 2018, pp. 634-647.

[9] Gartner, "The Importance of Citizen Development and Citizen IT," The Importance of Citizen Development, Oct. 10, 2019.

[10] B. R. Barricelli, F. Cassano, D. Fogli, and A. Piccinno, 2019. End-user development, end-user programming and end-user software engineering: A systematic mapping study. Journal of Systems and Software, 149, 101-137, 2019. 
[11] G. Fischer, D. Fogli, and A. Piccinno, "Revisiting and Broadening the Meta-Design Framework for End-User Development," in New Perspectives in End-User Development, 2017.

[12] Forrester, "The-Forrester-Wave-Low-CodeDevelopment-Platforms-For-ADD-Professionals-Q1-2019,"

[13] D. Durward, I. Blohm, B. Simmert, J. M. Leimeister, and C. Peters, "How to Empower the Workforce - Analyzing Internal Crowd Work as a Neo-Socio-Technical System -," p. 10.

[14] Tisi, M., Mottu, J.-M., Kolovos, D. S., de Lara, J., Guerra, E., Ruscio, D. D., Pierantonio, A., \& Wimmer, M., "Lowcomote: Training the Next Generation of Experts in Scalable Low-Code Engineering Platforms.," 2019.

[15] DePietro, R., Wiarda, E., and Fleisher, M., "The context for change: Organization, technology and environment," in The processes of technological innovation, Lexington Books: Massachusetts, U.S. A., 1990, 151-175.

[16] G Premkumar and K Ramamurthy, "he Role of Interorganizational and Organizational Factors on the Decision Mode for Adoption of Interorganizational Systems.," Decision Sciences, 26, 3, p303-336, 1995.

[17] Sapanda Argawal, Aaron De Smet, Pawel Poplawski, and Angelika Reich, "Beyond hiring: How companies are reskilling to adress talent gaps.," 2020.

[18] L. G. Tornatzky and K. J. Klein, "Innovation characteristics and innovation adoption-implementation: A meta-analysis of findings," IEEE Transactions on Engineering Management, vol. EM-29, no. 1, pp. 28-45, Feb. 1982.

[19] H. Gangwar, H. Date, and R. Ramaswamy, "Understanding determinants of cloud computing adoption using an integrated TAM-TOE model," Journal of Enterprise Information Management, vol. 28, no. 1, pp. 107-130, Jan. 2015.

[20] H. P. Borgman, B. Bahli, H. Heier, and F. Schewski, "Cloudrise: Exploring Cloud Computing Adoption and Governance with the TOE Framework," in 2013 46th Hawaii International Conference on System Sciences, Jan. 2013, pp. $4425-4435$.

[21] H. O. Awa and O. U. Ojiabo, "A model of adoption determinants of ERP within T-O-E framework," Information Technology \& People, vol. 29, no. 4, pp. 901-930, Jan. 2016. [22] B. Ramdani, P. Kawalek, and O. Lorenzo, "Predicting SMEs Adoption of Enterprise Systems," Journal of Enterprise Information Management, vol. 10-24, no. 22, p. 17, 2019.

[23] T. Oliveira, M. Thomas, and M. Espadanal, "Assessing the determinants of cloud computing adoption: An analysis of the manufacturing and services sectors," Information \& Management, vol. 51, no. 5, pp. 497-510, Jul. 2014.

[24] M. Alavi and I. R. Weiss, "Managing the Risks Associated with End-User Computing," Journal of Management Information Systems, vol. 2, no. 3, pp. 5-20, Dec. 1985.

[25] A. Greenshields, "Tech spend outside IT function creates opportunities, but opens back door to potential security and consumer trust risks - KPMG Global," $K P M G$, Jun. 12, 2019.

[26] T. Kajiyama, M. Jennex, and T. Addo, "To cloud or not to cloud: how risks and threats are affecting cloud adoption decisions," ICS, vol. 25, no. 5, pp. 634-659, 2017.
[27] D. Burda and F. Teuteberg, "The role of trust and risk perceptions in cloud archiving - Results from an empirical study," The Journal of High Technology Management Research, vol. 25, no. 2, pp. 172-187, 2014.

[28] F. Cruz-Jesus, A. Pinheiro, and T. Oliveira, "Understanding CRM adoption stages: empirical analysis building on the TOE framework," Computers in Industry, vol. 109, pp. 1-13, 2019.

[29] H.-Y. Hsu, F.-H. Liu, H.-T. Tsou, and L.-J. Chen, "Openness of technology adoption, top management support and service innovation: a social innovation perspective," Journal of Business \& Industrial Marketing, 34, 3, 575-590, 2019.

[30] J. Luftman and T. Brier, "Achieving and Sustaining Business-IT Alignment," California Management Review, vol. 42, no. 1, pp. 109-122, Oct. 1999.

[31] T. Coltman, P. Tallon, R. Sharma, and M. Queiroz, "Strategic IT Alignment: Twenty-Five Years on," Journal of Information Technology, 30, 2, 91-100, Jun. 2015.

[32] S. Charoensuk, W. Wongsurawat, and D. B. Khang, "Business-IT Alignment: A practical research approach," The Journal of High Technology Management Research, vol. 25, no. 2, pp. 132-147, 2014.

[33] S. D. Haes and W. V. Grembergen, "An Exploratory Study into IT Governance Implementations and its Impact on Business/IT Alignment," Information Systems Management, vol. 26, no. 2, pp. 123-137, Apr. 2009.

[34] P. Weill and J. W. Ross, IT governance: how top performers manage IT decision rights for superior results. Boston: Harvard Business School Press, 2004.

[35] R. Almeida, R. Pereira, and M. Mira da Silva, "IT Governance Mechanisms: A Literature Review," in Exploring Services Science, Berlin, Heidelberg, 2013, pp. 186-199.

[36] Peter Weill and Jeanne Ross, “A matrixed Approach to Designing IT Governance," MIT Sloan Management Review, 2005.

[37] A. Györy, A. Cleven, F. Uebernickel, and W. Brenner, "EXPLORING THE SHADOWS: IT GOVERNANCE APPROACHES TO USER-DRIVEN INNOVATION," ECIS 2012 Proceedings, May 2012.

[38] R. Alt and M. Smits, "Networkability of Organizations and Business Networks," p. 13.

[39] R. K. Yin, Case study research: design and methods, 5th ed. Thousand Oaks, CA: Sage, 2014.

[40] M. Saunders, P. Lewis, and A. Thornhill, Research Methods for Business Students. Pearson Education, 2009.

[41] "ATLAS.ti: The Qualitative Data Analysis \& Research Software," ATLAS.ti. https://atlasti.com/

[42] H. Lieberman, F. Paternò, M. Klann, and V. Wulf, "End-User Development: An Emerging Paradigm," in End User Development, vol. 9, H. Lieberman, F. Paternò, and V. Wulf, Eds. Dordrecht: Springer Netherlands, 2006, pp. 1-8. [43] R. Gsenger, S. Human, and G. Neumann, "End-user Empowerment: An Interdisciplinary Perspective," HICSS, p. $10,2020$.

[44] S. A. Brown, A. R. Dennis, and V. Venkatesh, "Predicting Collaboration Technology Use: Integrating Technology Adoption and Collaboration Research," Journal of Management Information Systems, vol. 27, no. 2, pp. 954, Oct. 2010. 